\title{
The Complete Plastid Genome of Magnolia zenii and Genetic Comparison to Magnoliaceae species
}

\author{
Yongfu Li ${ }^{1,2}$, Steven Paul Sylvester ${ }^{2}\left(\mathbb{0}\right.$, Meng Li ${ }^{1,2}{ }^{-}$, Cheng Zhang ${ }^{1,2}$, Xuan $\mathrm{Li}^{1}{ }^{1}$, \\ Yifan Duan ${ }^{1,2, *}$ and Xianrong Wang ${ }^{1,2, *}$ \\ 1 Co-Innovation Center for Sustainable Forestry in Southern China, Nanjing Forestry University, \\ Nanjing 210037, China; liyongfu1994@outlook.com (Y.L.); limeng@njfu.edu.cn (M.L.); \\ 18362928857@163.com (C.Z.); xuanli18851128817@163.com (X.L.) \\ 2 College of Biology and the Environment, Nanjing Forestry University, Nanjing 210037, China; \\ steven_sylvester@hotmail.com \\ * Correspondence: yifan419@hotmail.com (Y.D.); wangxianrong66@njfu.edu.cn (X.W.); Tel.: +86-25-8542-7428
}

Received: 11 November 2018; Accepted: 31 December 2018; Published: 11 January 2019

\begin{abstract}
Magnolia zenii is a critically endangered species known from only 18 trees that survive on Baohua Mountain in Jiangsu province, China. Little information is available regarding its molecular biology, with no genomic study performed on M. zenii until now. We determined the complete plastid genome of $M$. zenii and identified microsatellites. Whole sequence alignment and phylogenetic analysis using BI and ML methods were also conducted. The plastome of M. zenii was 160,048 bp long with $39.2 \%$ GC content and included a pair of inverted repeats (IRs) of 26,596 bp that separated a large single-copy (LSC) region of $88,098 \mathrm{bp}$ and a small single-copy (SSC) region of $18,757 \mathrm{bp}$. One hundred thirty genes were identified, of which 79 were protein-coding genes, 37 were transfer RNAs, and eight were ribosomal RNAs. Thirty seven simple sequence repeats (SSRs) were also identified. Comparative analyses of genome structure and sequence data of closely-related species revealed five mutation hotspots, useful for future phylogenetic research. Magnolia zenii was placed as sister to $M$. biondii with strong support in all analyses. Overall, this study providing M. zenii genomic resources will be beneficial for the evolutionary study and phylogenetic reconstruction of Magnoliaceae.
\end{abstract}

Keywords: traditional Chinese medicine; chloroplast genome; microsatellite; comparative analysis; phylogeny

\section{Introduction}

Magnolia zenii Cheng is listed as a critically endangered species in the IUCN Red List of Threatened Species (www.iucnredlist.org) due to there being only one population of 18 individuals existing on the northern slopes of the Baohua Mountain in Jiangsu, China. The small population of M. zenii is found within a provincial reserve, but no specific protective measures are given to this species. The survival of the species remains highly uncertain, with no natural regeneration being observed and no information available regarding seed viability. Current research on the conservation of the species has focused on intra- and inter-specific competition [1,2], vegetative propagation [3], and endogenous hormone production $[4,5]$. Projections of climate change [6], with temperatures likely to increase while precipitation is predicted to decrease, mean that the species may face a greater risk of extinction.

Aside from its conservation value, M. zenii has been found to have potential pharmaceutical value, with tomentosin (sesquiterpene lactone), one of the volatile components isolated from seeds of M. zenii, possibly having applications in the treatment of inflammatory diseases $[4,7,8]$. The species also has great potential as an ornamental tree due to being early flowering. 
Magnoliaceae, a family with approximately 335 species in 18 genera [9], is a core component of the Magnoliales and is distributed in temperate and tropical regions of eastern Asia and eastern North America to the Neotropics [10]. The Magnoliaceae family presents a classic Asian-North American disjunct distribution, with adequate fossil records all around Laurasia $[10,11]$. Members of the family also have relatively primitive flowers [12], which makes these taxa highly valuable for research in plant evolution and reproductive ecology [13-15]. There are widely differing opinions on the taxonomy of the Magnoliaceae, mainly regarding generic circumscription [16].

The genus Magnolia consists of about 70 plants distributed in temperate and tropical regions of eastern Asia and eastern North America to the Neotropics, among which 23 species are endemic to China [17]. This genus has been traditionally divided into subgenera Magnolia and Yulania Spach [18]. A further subgenus Michelia L. was proposed after preliminary phylogenetic studies revealed genus Michelia and subgenus Yulania were more closely related to each other than either one of them was to subgenus Magnolia [19]. Now, at least 11 well-supported sub-generic clades are recognized [20-22]. However, molecular research has found the genus to be paraphyletic, and support along the backbone of the Magnolia phylogeny is poor. This, coupled with the wide distribution of taxa within these subgeneric clades, alongside overlapping morphologies and no discrete boundaries in many morphological character states, has meant opinions on the subgeneric delimitation of Magnolia remain contentious.

The plastid genome (or "plastome") of all angiosperms has a quadripartite structure consisting of a large single-copy (LSC) region, a small single-copy (SSC) region, and two copies of larger inverted repeats (IRs) [23]. While often referred to as the "chloroplast genome", chloroplasts are just one type of plastid, along with leucoplasts, chromoplasts, and amyloplasts, which all develop from proplastids of an embryo and have an identical genome. The plastome varies in size from $75-250 \mathrm{~kb}$ and is highly conserved in terms of gene order and genome organization in flowering plants [24]. Hence, plastome sequences are widely used for exploring phylogenetic relationships in different plant groups [25,26]. However, some structural rearrangements have been discovered, such as gene or intron loss, and large inverted repeat (IR) expression $[27,28]$. Comparative analysis of plastomes can, thus, provide greater insight into the evolutionary history and interspecies relationships in the genus Magnolia.

In this study, we present the whole plastome sequence of $M$. zenii using Illumina sequencing technology and explore its relationships with other species within the genus. These results will be helpful for phylogenetic studies, while expanding horizons regarding the structural diversity of the plastome, as well as phylogenetic studies of Magnoliaceae species.

\section{Results and Discussion}

\subsection{Genome Features and Guanine-Cytosine Content}

The full-length plastome of M. zenii was $160,048 \mathrm{bp}$, which is slightly larger than that of the closely-related species Magnolia biondii Pamp. (160,002 bp) (Table S1). The plastome length in other species of Magnolia ranges narrowly from 158,177 bp in Magnolia liliiflora Desr. to 160,183 bp in Magnolia officinalis Rehder \& E.H. Wilson (Table S1) [29]. The plastid structure of M. zenii was a typical quadripartite circular molecule (Figure 1) that resembles the plastomes of the majority of angiosperms, which includes a large single-copy (LSC) region of 88,098 bp and a short single-copy (SSC) region of $18,757 \mathrm{bp}$ divided into a pair of inverted repeat (IR) regions, IRA (26,596 bp) and IRB (26,596 bp) (Figure 1 and Table S1). 


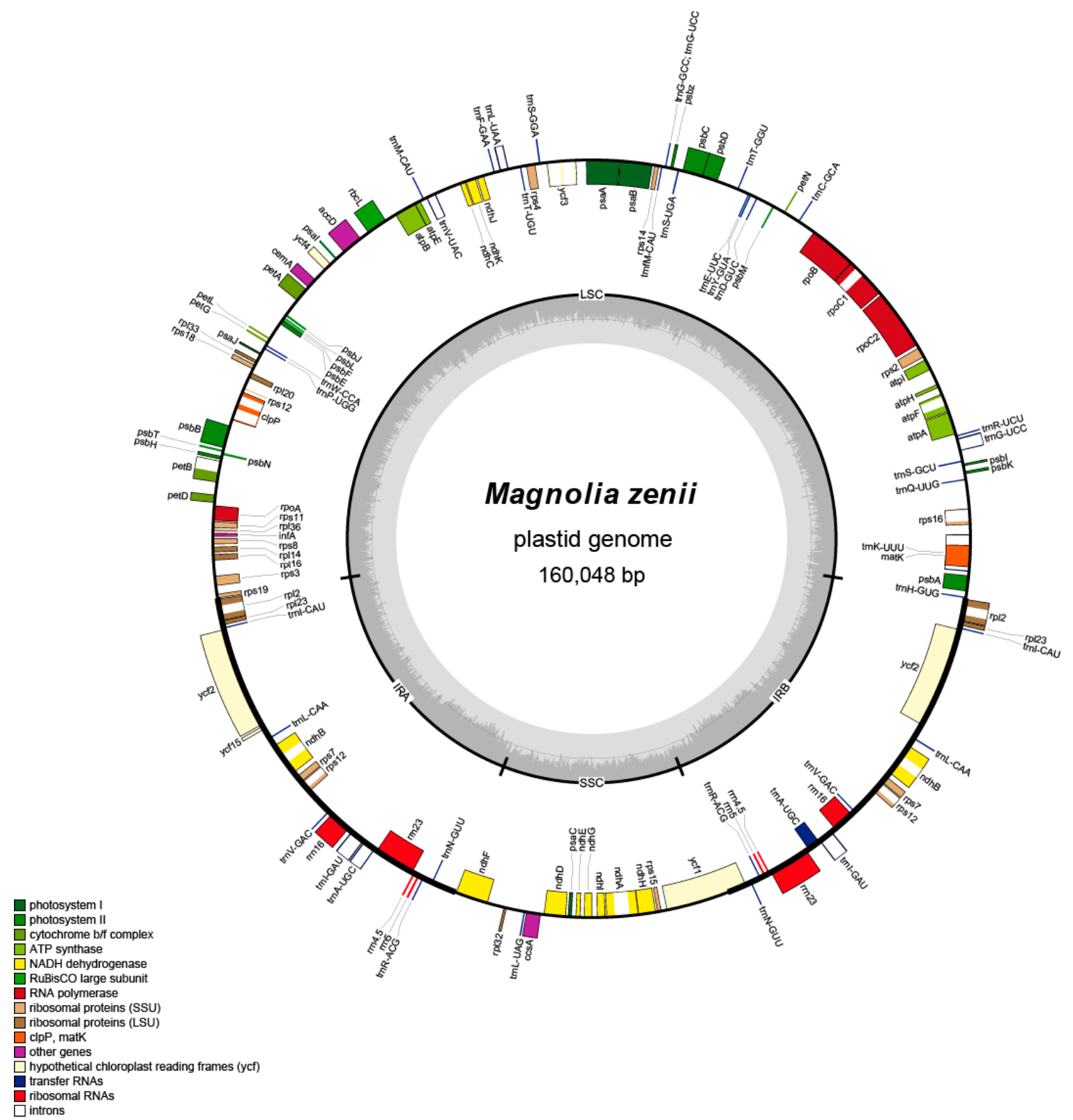

Figure 1. Plastid genome map of M. zenii. Genes inside the circle are transcribed clockwise, and those outside are transcribed counterclockwise. Genes of different functions are color-coded. The darker gray in the inner circle shows the GC content, while the lighter gray shows the AT content.

The percentage GC content of the total plastid DNA sequence is 39.2\% (Table S1 and Table S2). The GC content of the LSC and SSC regions is $37.9 \%$ and $34.1 \%$, respectively, while the IRA and IRB regions showed higher GC contents, with both at $43.2 \%$, which is similar to other species of Magnolia such as M. grandiflora L. (Table S1) [30]. The higher GC content in the IR region compared with the SSC and the LSC regions is probably due to the presence of four ribosomal RNA genes duplicated in this region [31]. In fact, the overall GC content is often associated with the degree of primitiveness of a taxon: early-diverging lineages, such as magnoliids, tend to have a higher GC content compared to the average $35 \%$ GC content of most angiosperms [32]. The M. zenii plastome is AT-rich, which is consistent with other species of Magnolia; for instance, M. grandiflora (60.7\%), M. officinalis (60.78\%), M. kwangsiensis Figlar \& Noot. (60.74\%) [30], and other species like Liriodendron tulipifera L. (60.84\%) [30], Acer miaotaiense P.C. Tsoong (62.12\%), Citrus sinensis (L.) Osbeck (61.52\%) and Phellodendron amurense Rupr. (61.60\%) [31]. 
A total of 130 distinct genes were annotated, including 37 transfer RNAs (tRNA), 8 ribosomal RNAs (rRNA), and 84 protein-coding genes (Table 1 and Table S1). Five genes were duplicated in the IRs including trnA-UGC, trnI-GAU, rps12, rpl2, and $n d h B$. These genes are identical to those found in M. grandiflora [30]. The rps12 is a specific trans-splicing gene of which the $5^{\prime}$-end exon is located in the LSC region, and the intron and $3^{\prime}$-end exon of the gene are situated in the IRs regions. Intron splicing is known to cause enhancement of gene expression [33], and spliceosomal introns are a landmark feature of eukaryotic nuclear genes [34]. Removal of these introns by the spliceosome can influence many other stages of mRNA metabolism, such as editing and polyadenylation of the pre-mRNA [35]. There were 17 intron-containing genes in the plastome of $M$. zenii, of which three genes (rps12, ycf3, and $\operatorname{clpP}$ ) had two introns and the rest had one intron (Table S3). For many magnoliid species, such as M. grandiflora, M. kwangsiensis, Drimys J.R. Forst. \& G. Forst. and Piper L., these same three genes $(r p s 12, y c f 3$, and $\operatorname{clpP})$ have two introns. Gene ycf1 was the only pseudogene located in the junction between the SSC and IRB regions and was formed by the incomplete duplication of the normal copy $y c f 1$. In general, the genes of $M$. zenii and related species are very similar, most likely due to the very slow rates of genome evolution in Magnoliaceae [29,36].

Table 1. List of genes annotated in the plastomes of M. zenii sequenced in this study.

\begin{tabular}{|c|c|c|c|c|c|c|}
\hline \multicolumn{2}{|r|}{ Category } & \multicolumn{2}{|c|}{ Name of Group } & \multicolumn{3}{|c|}{ Name of Gene } \\
\hline \multirow{5}{*}{ Self-replication } & Ribosomal RNA & $r r n 16$ & $\operatorname{rrn} 23$ & rrn4.5 & rrn5 & \\
\hline & Transfer RNA & $\begin{array}{c}\operatorname{trn} A-U G C \\
\text { trnfM-CAU } \\
\text { trnI-GAU } \\
\text { trnM-CAU } \\
\text { trnR-UCU } \\
\text { trnT-UGU }\end{array}$ & $\begin{array}{c}\operatorname{trnC-GCA} \\
\operatorname{trn} G-G C C \\
\operatorname{trnK}-U U U \\
\operatorname{trn} N-G U U \\
\operatorname{trnS}-G C U \\
\operatorname{trn} V-G A C\end{array}$ & $\begin{array}{l}\operatorname{trnD-GUC} \\
\operatorname{trnG}-U C C \\
\operatorname{trnL-CAA} \\
\operatorname{trn} P-U G G \\
\operatorname{trnS}-G G A \\
\operatorname{trn} V-U A C\end{array}$ & $\begin{array}{l}\text { trnE-UUC } \\
\text { trnH-GUG } \\
\operatorname{trnL-UAA} \\
\operatorname{trn} Q-U U G \\
\operatorname{trnS}-U G A \\
\operatorname{trn} W-C C A\end{array}$ & $\begin{array}{l}\text { trnF-GAA } \\
\text { trnI-CAU } \\
\text { trnL-UAG } \\
\text { trnR-ACG } \\
\text { trnT-GGU } \\
\operatorname{trn} Y-G U A\end{array}$ \\
\hline & Small subunit of ribosome & $\begin{array}{c}\text { rps11 } \\
\text { rps18 } \\
\text { rps7 }\end{array}$ & $\begin{array}{c}\text { rps12 } \\
\text { rps19 } \\
\text { rps8 }\end{array}$ & $\begin{array}{c}\text { rps14 } \\
\text { rps2 }\end{array}$ & $\begin{array}{c}\text { rps15 } \\
\text { rps3 }\end{array}$ & $\begin{array}{c}\text { rps16 } \\
\text { rps4 }\end{array}$ \\
\hline & Large subunit of ribosome & $\begin{array}{l}\text { rpl12 } \\
\text { rpl23 }\end{array}$ & $\begin{array}{l}\text { rpl14 } \\
\text { rpl32 }\end{array}$ & $\begin{array}{l}\text { rpl16 } \\
\text { rpl33 }\end{array}$ & $\begin{array}{c}\text { rpl2 } \\
\text { rpl36 }\end{array}$ & rpl20 \\
\hline & RNA polymerase subunits & rpoA & rpoB & rpoC1 & rpoC2 & \\
\hline \multirow{6}{*}{ Photosynthesis } & Subunits of photosystem I & $p s a A$ & $p s a B$ & $p s a C$ & psaI & psaJ \\
\hline & Subunits of photosystem II & $\begin{array}{l}p s b A \\
p s b F \\
p s b L\end{array}$ & $\begin{array}{l}p s b B \\
p s b H \\
p s b M\end{array}$ & $\begin{array}{c}p s b C \\
p s b I \\
p s b N\end{array}$ & $\begin{array}{c}p s b D \\
p s b J \\
p s b T\end{array}$ & $\begin{array}{l}p s b E \\
p s b K \\
p s b z\end{array}$ \\
\hline & Subunits of cytochrome & $\begin{array}{l}\operatorname{pet} A \\
\operatorname{pet} N\end{array}$ & petB & petD & $\operatorname{pet} G$ & petL \\
\hline & Subunits of ATP synthase & $\begin{array}{c}\text { atp } A \\
\text { atpI }\end{array}$ & $\operatorname{atpB}$ & atpE & $\operatorname{atpF}$ & $\operatorname{atpH}$ \\
\hline & Large subunit of RuBisCO & $r b c L$ & & & & \\
\hline & Subunits of NADH & $\begin{array}{l}n d h A \\
n d h F \\
n d h K\end{array}$ & $\begin{array}{l}n d h B \\
n d h G\end{array}$ & $\begin{array}{l}n d h C \\
n d h H\end{array}$ & $\begin{array}{c}n d h D \\
n d h I\end{array}$ & $\begin{array}{c}n d h E \\
n d h J\end{array}$ \\
\hline \multirow{6}{*}{ Other gene } & Translational initiation factor & $\inf A$ & & & & \\
\hline & Maturase & matK & & & & \\
\hline & Envelope membrane protein & $\operatorname{cem} A$ & & & & \\
\hline & Subunit of acetyl-CoA & $a c c D$ & & & & \\
\hline & C-type cytochrome synthesis gene & $\operatorname{ccs} A$ & & & & \\
\hline & Protease & $\operatorname{clpP}$ & & & & \\
\hline Unknown function & Conserved open reading frames & $y c f 1$ & ycf15 & $y c f 2$ & $y c f 3$ & $y c f 4$ \\
\hline
\end{tabular}

\subsection{Codon Usage Bias}

Based on theCoding sequence (CDS), the codon usage frequency (relative synonymous codon usage (RSCU) was estimated for the plastome of $M$. zenii (Table S4). All the protein-coding genes presented a total of 26,266 codons, leucine (2681 codons, approximately $10.20 \%$ of the total) being the 
most abundant amino acid in the M. zenii plastome. This is followed by isoleucine with $8.44 \%$, while cysteine was rare with only $1.17 \%$. Our findings match the trend reported across other angiosperm plastomes, which show leucine and isoleucine to be the most common [37,38]. Moreover, Met (AUG), TER (UGA), and Trp (UGG) are encoded by only one codon, which means they showed no codon bias. Besides that, almost all of the A/U-ending codons had RSCU values of more than one $(R S C U>1)$, whereas the C/G-ending codons had RSCU values of less than one.

\subsection{Repeat Sequences}

Microsatellites are chosen as ideal genetic markers in plant molecular studies such as Papaver rhoeas L. [39], Lilium henrici Franchet [37], and Rosa chinensis var. spontanea (Rehder \& E.H. Wilson) T.T. Yu \& T.C. $\mathrm{Ku}$ [38], because of their high variability. Microsatellites are usually $\leq 15 \mathrm{bp}$-long tandem repeat DNA sequences and are distributed throughout the genome [40]. The generally uniparental mode of plastid inheritance, which is usually maternal inheritance in angiosperms and paternal inheritance in gymnosperms, makes them powerful tools to elucidate relative contributions of seed and (or) pollen flow [41] to the genetic structure of natural populations of seed plants such as Quercus L. [42]. In this study, simple sequence repeats (SSRs) were detected in the plastome of M. zenii (Table S5). A total of 37 SSRs were identified. No pentanucleotide repeats were found. Mononucleotide SSRs were the richest $(72.29 \%)$, and the mononucleotide A and T repeat units occupied the highest portion (96.67\%). Our findings agree with the observation that plastid SSRs are generally composed of polyadenine (poly A) and polythymine (poly $\mathrm{T}$ ) and rarely contain tandem guanine $(\mathrm{G})$ and cytosine $(\mathrm{C})$ repeats [43]. In addition, we found that mononucleotide, dinucleotide, and trinucleotide repeats were composed of a higher level of $\mathrm{A}$ or $\mathrm{T}$; this contributed to a bias in base composition, which was consistent with the overall A-T richness (60.7\%) of the plastome. The bias may have been caused by the ability of A to convert to T more readily than G-C in the genome [44].

A total of 50 long repeats were discovered in the $M$. zenii plastome (Table S6). This included 35 forward $(\mathrm{F})$ repeats and 15 palindromic $(\mathrm{P})$ repeats, while no tandem repeats were found. Among these, 35 forward repeats were 16-57 bp in motif length, and 15 palindromic repeats were 17-21 bp long. Most of the long repeats were located in the ycf gene and intergenic spacers (IGS). As with the SSRs, M. zenii also contained a lower number of long-repeat elements compared with other species. The presence of these repeats indicates that the locus is likely to be a crucial mutation hotspot in the genome because the repeat sequences allow sequence variations and genome rearrangements through slipped-strand mispairing and improper recombination [45].

\subsection{Comparative Analysis of Plastomes of Magnolia Species}

Complete genome alignment using Mauve software was done for 28 species of Magnolia (Table S1) and two species of Liriodendron (Figure 2). Whole-genome alignment of the plastomes revealed a common syntenic break at inverted repeat regions ( 90,000-115,000; 135,000-145,000), which also showed the highest variation in gene structure among the aligned plastomes. In general, the locally-collinear blocks (LCBs) depicted all these species to maintain a consistent position and direction in most of the genes, and no rearrangement or inversion events were found. Some other studies have suggested homology in plastome organization and no gene rearrangements in many plant groups $[32,46]$, and our findings support their conclusions. 


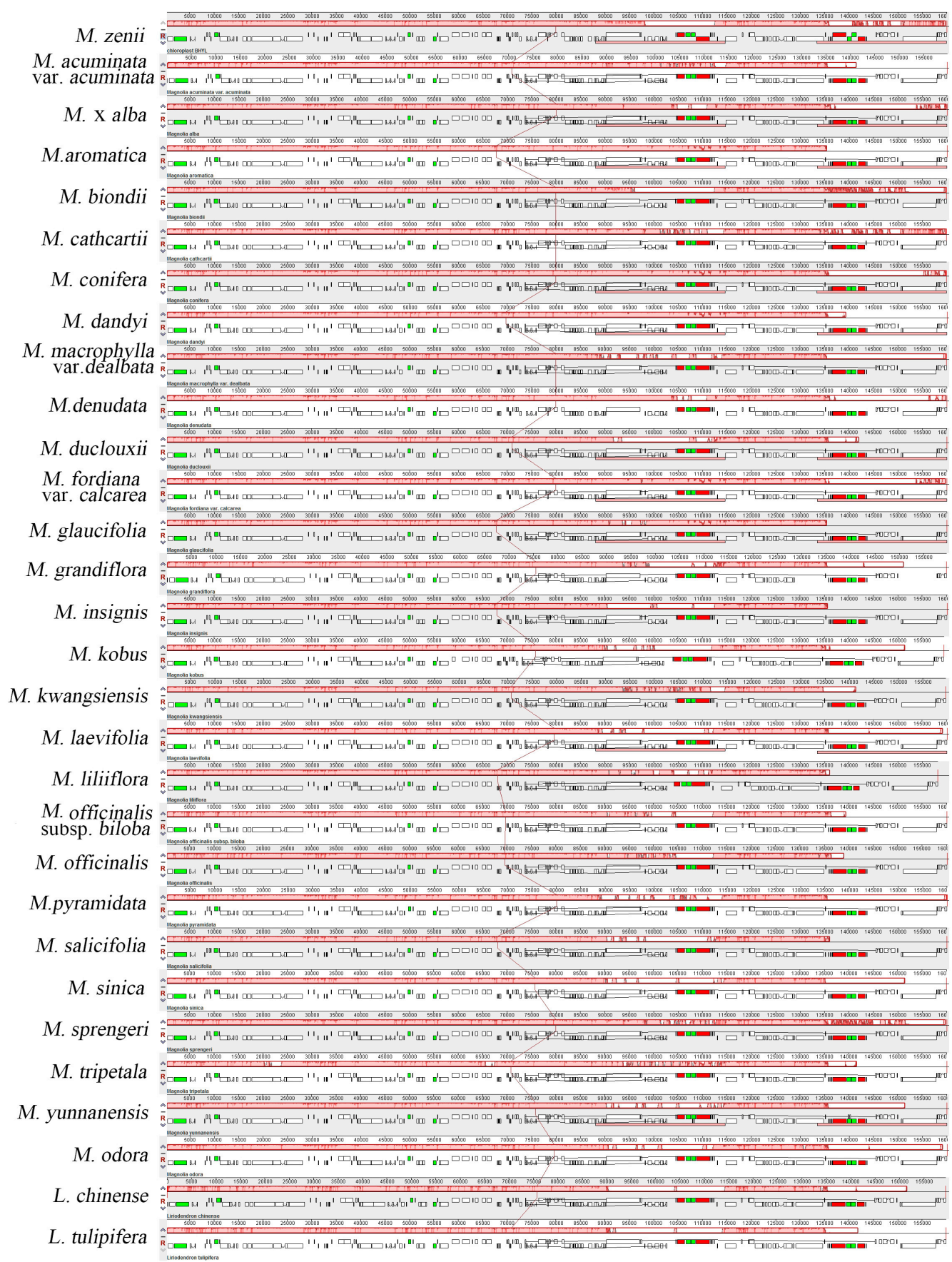

Figure 2. Mauve (Multiple Alignment of Conserved Genomic Sequence With Rearrangements) [47] alignment of plastid genomes of 28 species of Magnolia and two species of Liriodendron. The M. zenii genome is shown at the top as the reference genome. Within each of the alignments, local collinear blocks are represented by blocks of the same color connected by lines.

Comparison of DNA sequences from 30 species of Magnoliales is a fundamental method for identifying functional elements in genomes. The LAGAN (Limited Area Global Alignment of Nucleotides) [48] global alignment indicated that the IR regions are more conserved than the LSC and SSC regions (Figure S1). Rates of nucleotide substitution were previously shown to be several times slower in the plastid IR regions compared with SC regions in other angiosperms, suggesting that IR regions provide enhanced copy-correction activity [49]. Gene conversion has been shown to be biased towards copy-dependent repair mechanisms [50]. This phenomenon is possibly due to error correction occurring via gene conversion between Irs [51]. Furthermore, within the LSC and 
SSC regions, coding regions were more conserved than non-coding regions among the 30 plastomes. However, significant variations were found in coding regions of some genes including matK, $\operatorname{trn} H$ - $p s b A$, $n d H h, y c f 1$, and $y c f 2$. In Orchidaceae, $y c f 1$ is identified as more variable and informative than matK at the species level, while also being easier to align than ITS genes [52]. ycf2 is the largest plastid gene in angiosperms, although some species such as rice and maize [53] are reported to have independently lost this gene. The function of $y c f 2$ is largely unknown, but it appears to provide a good phylogenetic signal for resolving problems in plant phylogenies due to its long sequence length and low rate of nucleotide substitution [54]. Therefore, $y c f 1$ and $y c f 2$ may be potentially useful for phylogenetic research in Magnolia.

\subsection{Junction Characteristics}

The size variation of angiosperm plastid genomes is primarily due to expansion and contraction of the IR and SSC boundary regions [53,55]. Detailed comparisons of the IR/SSC and IR/LSC junction sites between the Magnolia and Liriodendron species are presented in Figure 3. Generally, the IRA/LSC border is located between the $r p l 2$ and $t r n H$ genes in Magnolia, with rpl2 in IRA and trnH in LSC, like that found in Rosa roxburghii Tratt. and Rosa odorata (Andr.) Sweet var. gigantea (Crép) Rehd. et Wils. [38]. The trnH gene of $M$. zenii extends only eight bp in length from LSC to IRA. The lengths of the LSC, IR, and SSC regions were similar in the plastomes of the 30 species studied. The JLB (IRB/LSC) border was located in the coding region of rps19. The ycf1 gene spanned the JSA (SSC/IRA) region, and its length also reflected changes in the JSA region. Magnolia dandyi Gagnep. had the longest ycf1 sequence with $5630 \mathrm{bp}$, while Liriodendron chinense (Hemsl.) Sarg. had the shortest sequence of 5489 bp. The NdhF gene deviated from the JSB (IRB/SSC) region in the species studied, ranging from $51 \mathrm{bp}$ in Magnolia acuminata (L.) L. [56] to $93 \mathrm{bp}$ in M. officinalis [30]. Indeed, ycf1 was considered to have a close relationship to the position of the IR border in previous studies of Magnoliaceae species [30]. The tRNA gene trnH-GUG was located in the LSC, which ranged from 8-24 bp from the JLA (IRA/LSC) border. Apart from the ribosomal operon, IR gene content varies among angiosperms due to expansion and contraction of the IR/SC boundaries. Although many studies have reported changes in plastid genomes, including gene loss [57,58], inversion or deletions [59,60], and expansion or contraction of the IR region [61], in this study, IR boundary shifts tended to be relatively minor, involving just a small number of genes, and the position of the $t r n H$ gene located at the junction of IRA/LSC only presented irregular shifting. The highest divergence in non-coding regions was located in the intergenic regions of rps16-trnQ, $\operatorname{trnS}-\operatorname{trn} G$, and $n d h F-r p l 32$. These regions were also identified as phylogenetically informative for studying the classification and evolutionary drift in other plant groups $[62,63]$. 


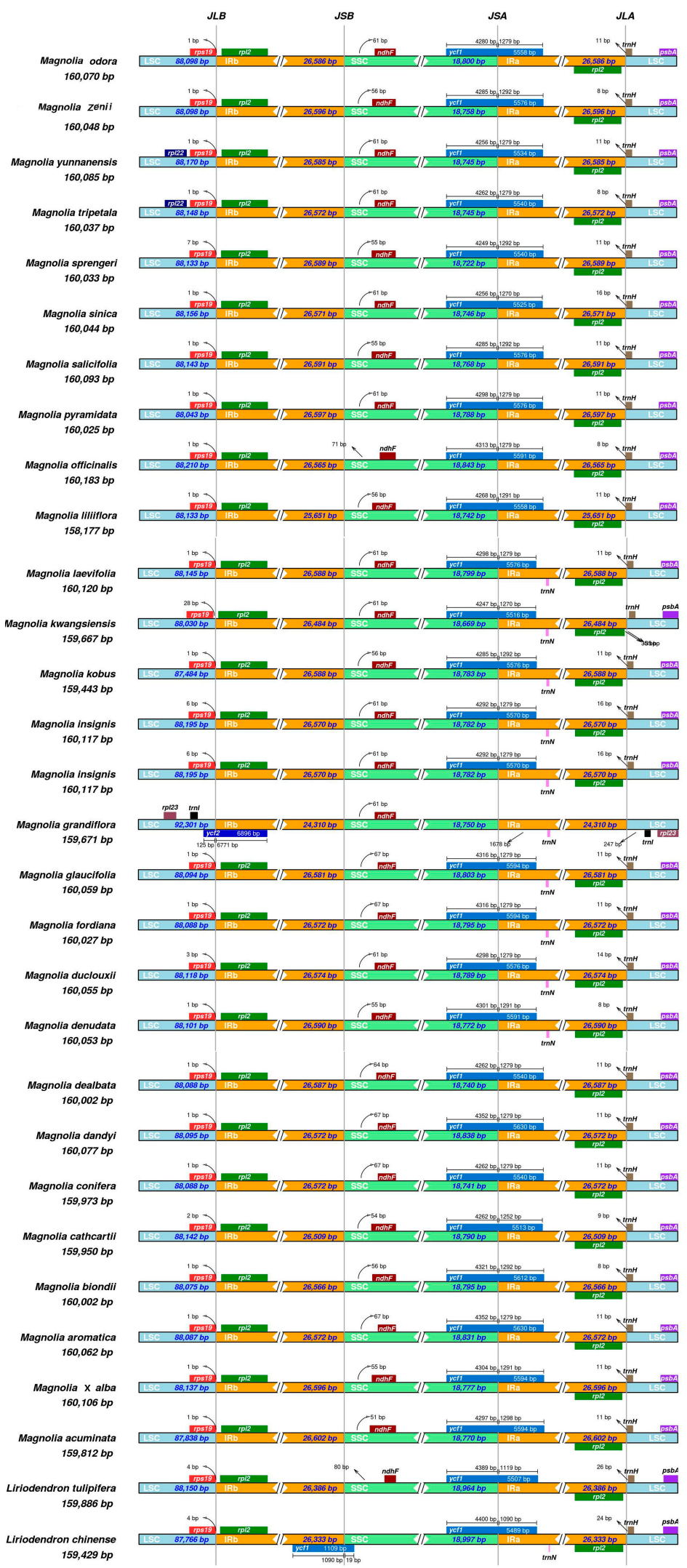

Figure 3. Comparison of the large single-copy (LSC), short single-copy (SSC), and inverted repeat (IR) regions in plastomes of 27 Magnolia (represented by 28 individual genomes including two M. insignis genomes) and two Liriodendron species. Genes are denoted by colored boxes. The gaps between the genes and the boundaries are indicated by the base lengths (bp). 


\subsection{Phylogenetic Inference}

To examine the phylogenetic position of $M$. zenii within the Magnolia genus, we selected complete plastid genome sequences from the plastomes of 28 Magnolia (represented by 36 individual sequences) and two Liriodendron species. In the ML and BI trees, most of the nodes had $100 \%$ bootstrap support and 1.0 Bayesian posterior probability (Figure 4 and Figure S2). BI analysis found that 25 of 36 nodes had posterior probability values of $\geq 99 \%$ (Figure 4 ), and 26 of these 36 nodes had $100 \%$ bootstrap support in ML analyses (Figure S2). Both the ML and BI trees had identical phylogenetic topologies, which strongly support the position of M. zenii as a sister to M. biondii in the subgenus Yulania (Figure 4). This position of M. zenii is in line with the previously-published phylogeny of Kim et al. [20,21], while Figlar [64] only provided a broad classification, placing M. zenii in section Yulania, and did not discuss relationships between species. Phylogenetic research using nuclear datasets [22] also found M. zenii to be nested within section Yulania, but placed as a sister to a clade comprising M. denudata Desr., M. liliiflora, M. dawsoniana Rehder \& E.H. Wilson, and M. sprengeri Pamp. It is interesting to note, however, that the Flora of China [16] states M. elliptigemmata C.L. Guo \& L.L. Huang to be the species most similar morphologically to M. zenii, although no molecular samples exist for M. elliptigemmata to explore its phylogenetic relationships.
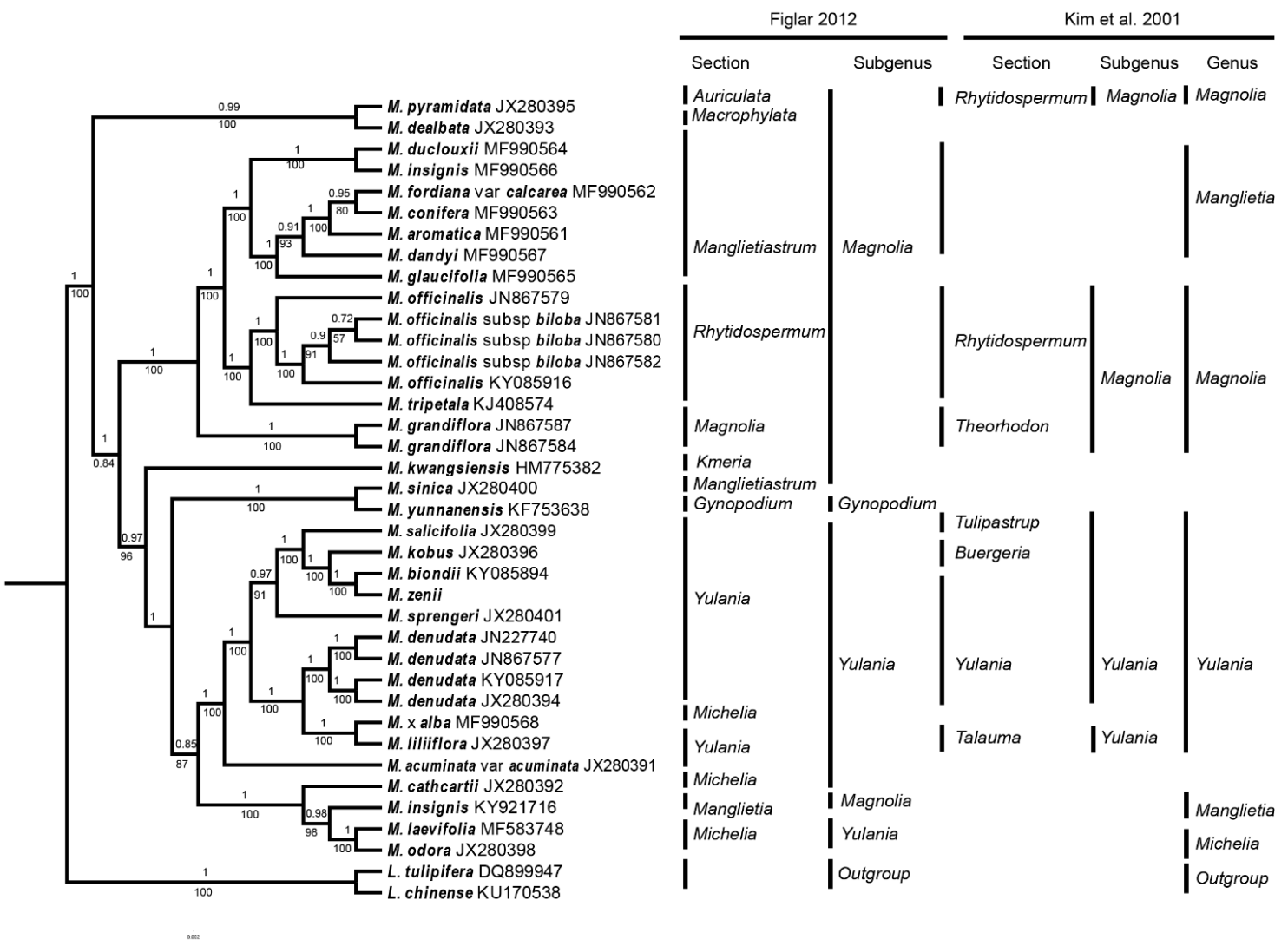

Figure 4. BI phylogenomic tree of 28 Magnolia (represented by 36 individuals) and 2 Liriodendron species. Numbers above the lines indicate the posterior probability of each clade, and numbers below the lines indicate the likelihood bootstrap values. The vertical lines on the right of the phylogenomic tree show the subgeneric taxonomic placement of these species according to Kim et al. [21] and Figlar [64].

Furthermore, early-diverging species, M. pyramidata W. Bartram and M. dealbata Zucc., belonged to sections Auriculata Figlar \& Noot. and Macrophylla Figlar \& Noot., respectively. These two species, both endemic to North America, formed monophyletic clades with $100 \%$ bootstrap support in the ML analyses (Figure S2) and 0.99 Bayesian posterior probability in BI analyses. In addition, M. insignis was placed as a sister to section Michelia with $96 \%$ posterior probability and bootstrap support in both the 
BI and ML trees, which conflicts with the results of Kim et al. [21]. As species previously treated as Michelia, i.e., Magnolia alba (DC.) Figlar and M. odora (Chun) Figlar \& Noot., were found to be placed in different parts within the Yulania clade, this supports Figlar et al. [19], sinking Michelia into Magnolia, but does not corroborate the recognition of subgenus Michelia [22]. Although our taxon sampling was insufficient to perform a robust phylogenetic analysis of Magnolia, our data do provide information for future phylogenetic studies within the genus. Our discovery of gene regions with high polymorphism not used by previous phylogenetic studies in Magnolia [11,20-22,65] provides exciting avenues for future phylogenetic and evolutionary studies in this genus. It is now necessary that work be done to design the markers for these mutation hotspots to test their value in molecular studies.

\section{Materials and Methods}

\subsection{DNA Extraction and Sequencing}

Fresh M. zenii leaves were collected from one of the three M. zenii trees growing in the Nanjing botanical garden, Jiangsu province, China. Total genomic DNA was extracted using the modified cetyl trimethyl ammonium bromide (CTAB) method [66]. Following this, the sample genomic DNA was fragmented by mechanical disruption (ultrasound), and then, the fragmented DNA was subjected to fragment purification, end repair, $3^{\prime}$ end plus $\mathrm{A}$, and ligation sequencing, and then, agarose gel electrophoresis was used to detect DNA integrity and quality. The fragment size was selected by electrophoresis, and the sequencing library was formed by PCR amplification. The constructed library was first subjected to library quality inspection, and the qualified library was sequenced by Illumina HiSeq platform technology. The quality and quantity of the genomic DNA were evaluated using the Nanodrop detection method. The experimental process was carried out in accordance with the standard protocol provided by the manufacturer's instructions (Illumina Biotechnology company, San Diego, CA, USA), including sample quality testing, library construction, library quality testing, and library sequencing. Then, 41,103,536 raw reads were sequenced with paired-end (PE) 150 bp-length reads.

\subsection{Chloroplast Genome Assembling and Annotation}

Raw data were filtered, and high-quality clean data were obtained by removing the connector sequence and low-quality reads. The plastome was assembled via NOVOPlasty [67], with published Magnolia species as references. The annotation of rRNAs, tRNAs, and protein-coding genes of the plastome was performed using the CPGAVAS pipeline [68] and then manually corrected. OGDRAW [69] was used to visualize the structural features of the M. zenii plastome. The relative synonymous codon usage (RSCU) was examined using CodonW [70]. The annotated plastid genome sequence of M. zenii was deposited in GenBank (Accession number MH607378).

\subsection{Whole Plastid Genome Comparison}

To research genome-wide evolutionary dynamics in Magnolia and Liriodendron to reconstruct evolutionary events such as gene loss, duplication, rearrangement, and horizontal transfer, multiple genome alignments were done using Mauve software [71]. mVISTA [72,73] was used to find conserved sequences for functionally-significant regions. Thirty plastomes, including 28 Magnolia and 2 Liriodendron species were compared by the Shuffle-LAGAN alignment algorithm [74], using the plastome of Magnolia laevifolia (Y.W. Law \& Y.F. Wu) Noot. as a reference. Irscope [75] was used to draw the genetic architecture of 10 Magnolia genomes in the junction of the sites connecting the IR regions to the LSC and SSC regions. DNA sequence variation within Magnolia was calculated by the DnaSP program [76] with the sliding window method in noncoding, synonymous, or nonsynonymous sites.

\subsection{Repeat Structure Identification}

The online software Reputer $[77,78]$ was used to identify the repeat sequences ( $\mathrm{n} \geq 30 \mathrm{bp}$; sequence identity $\geq 90 \%$ ). Four matches of repeats were classified into the following categories: (i) forward 
(direct) match, (ii) reverse match, (iii) complement match, and (iv) palindromic match. Simple sequence repeats (SSRs) were examined by Perlscript MISA [79] to detect mono-, di-, or tri-microsatellites.

\subsection{Phylogenetic Analysis}

Phylogenies were constructed by maximum likelihood (ML) and Bayesian inference (BI) analysis using 38 plastomes of 28 Magnolia (represented by 36 individuals) and 2 Liriodendron species (Figure 4, Figure S2, Table S1). The sequences were initially aligned using MAFFT [80] and then visualized and manually adjusted using BioEdit [81]. JmodelTest2 [82] was used to evaluate and select the best-fitting models of nucleotide sequences. A General Time Reversible + Proportion Invariation + Gamma nucleotide substitution model $($ GTR $+\mathrm{I}+\mathrm{G})$ were selected as the best substitution models for the ML and BI analyses. The Akaike information criterion [83] was used to select among models instead of the hierarchical likelihood ratio test, following Pol [84] and Posada and Buckley [85]. ML analyses were conducted in RaxML-HPC2 on TG ver. 7.2.8 on the Cipres web server [86,87], with 1000 rapid bootstrap analyses along with a search for the best-scoring tree in every run. BI analyses were conducted using Mrbayes v 3.2.6 [88], with two independent Markov chain Monte Carlo (MCMC) analyses run, each with three heated and one cold chain for 1,000,000 generations. Each chain started with a random tree; priors were set to default; and trees were sampled every 100 generations, with the first $25 \%$ discarded as burn-in. Calculations of the consensus tree, including clade posterior probability (PP), were performed based on the trees sampled after the chains converged.

\section{Conclusions}

Using Illumina high-throughput sequencing technology, we obtained the first complete plastome sequence of the critically endangered species, M. zenii. The plastid genome had a typical quadripartite structure with a conserved arrangement, the gene content and gene order being consistent with those found in plastomes of magnoliids and other typical angiosperms. Comparison of genome structure suggested that variation in the plastid genome structure of Magnoliaceae taxa is very limited, with almost no gene inversion or rearrangement found, which is consistent with previous studies [30]. This highly conserved plastome content implies that the plastid genome evolves very slowly in Magnoliaceae species, with $M$. zenii and its congeners a good study system for future investigation over the possible reasons for this slow genome evolution. While determining the distribution and location of repeat sequences, five regions of mutation hotspots at the level of genus and tribe were detected, which will be valuable for future molecular studies. Future research should now be conducted to design the markers for these mutation hotspots to test their value in phylogenetic studies. This is especially pertinent seeing as subgeneric relationships within Magnolia remain contentious, with the genus found to be paraphyletic and support along the backbone of the Magnolia phylogeny is poor [20-22]. The ML and BI phylogenetic trees strongly supported M. zenii as a member of the section Yulania and as a sister to $M$. biondii, but further studies should now be done using a more comprehensive taxon sampling that includes, e.g., morphologically-similar species such as M. elliptigemmata [15], to elucidate the classification and evolutionary history of this species.

The repeat motifs and mutation hotspots identified in the plastome can now be used to develop markers for population genetic studies and pave the way for more applied research focused on the monitoring and conservation of genetic diversity in wild populations of $M$. zenii that will be essential to the species' long-term survival [89]. This unique tree has much horticultural and medicinal value, with there being great potential for conservation practices to bring the species back from the brink of extinction, including sourcing propagules for threatened species reintroductions and ecological restoration [90]. However, such strategies require an understanding of small population processes and inbreeding depression, local adaptation, and outbreeding depression [90,91], which can only be gained through careful monitoring of the species genetic resources, with our study providing important information to facilitate this. 
Supplementary Materials: The following are available online: Table S1: Summary of the plastid genome features of the 28 Magnolia and 2 Liriodendron species studied, Table S2: Base composition in the M. zenii plastid genome, Table S3: The length of exons and introns in genes with introns in the M. zenii plastid genome, Table S4: Codon-anticodon recognition patterns and codon usage of the M. zenii plastid genome, Table S5: Simple sequence repeats (SSRs) in the M. zenii plastid genome, Table S6. Long repeat sequence in the M. zenii plastid genome, Figure S1: Complete plastid genome comparison of 28 Magnolia and two Liriodendron species using the plastome of $M$. laevifolia as a reference. The grey arrows and thick black lines above the alignment indicate the genes' orientation. The $y$-axis represents the percent identity between 50 and $100 \%$. Red and blue areas indicate intergenic and genic regions, respectively, Figure S2: ML phylogenomic tree of 28 Magnolia (represented by 36 individuals) and 2 Liriodendron species. Numbers above the lines indicate the bootstrap support of each clade when $>50 \%$.

Author Contributions: Y.L., M.L., and Y.D. conceived of and designed the research framework; Y.L. and X.L. performed most of the experiments and data analysis; Y.L., S.P.S., and X.L. wrote the original draft manuscript; S.P.S. and Y.L. reviewed and edited the final manuscript; Y.L. and C.Z. assembled and annotated the genome; Y.L. and C.Z. collected the samples; X.W. and Y.D. supervised the project and provided suggestions for the manuscript.

Funding: The study was partially supported by the Natural Science Foundation of Jiangsu Province (No. BK20160932), China Postdoctoral Science Foundation (No. 2016M590462), and the Natural Science Fund for Colleges and Universities in Jiangsu (No. 15KJB180007).

Acknowledgments: The authors are grateful to the six anonymous reviewers for their suggestions for improving the manuscript.

Conflicts of Interest: The authors declare no conflict of interest.

\section{References}

1. Wang, J.W.; Zhang, G.-F.; Chen, H.-Y. Population pattern and community characteristics of endemic and rare plant Magnolia zenii in Baohuashan National Forest Park. Guihaia 2008, 28, 489-494.

2. Mei, J.G.; Guo, S.; Fu, Z.G.; Wei, W.J. Intra-and interspecific competition of endangered plant Magnolia zenii. Chinese J. Ecol. 2010, 29, 201-206.

3. Shubin, Z. Study on Cuttage Propagation Technique of Magnolia zenii. J. Shandong For. Sci. Technol. 2008, 3. Available online: http://en.cnki.com.cn/Article_en/CJFDTotal-TREE200806014.htm (accessed on 9 November 2018).

4. Song, X.; Li, J.; Li, Z. GC-MS analysis of volatile components from bark of Magnolia zenii. Pract. Pharm. Clin. Remedies 2012, 15, 651-652.

5. Song, X.K.; Jing, L.I.; Li, Z.-H. GC-MS analysis of volatile components from seeds of Magnolia zenii Cheng. Pract. Pharm. Clin. Remedies 2012. Available online: http://en.cnki.com.cn/Article_en/CJFDTOTALLYLC201210018.htm (accessed on 9 November 2018).

6. Attorre, F.; Abeli, T.; Bacchetta, G.; Farcomeni, A.; Fenu, G.; De Sanctis, M.; Gargano, D.; Peruzzi, L.; Montagnani, C.; Rossi, G.; et al. How to include the impact of climate change in the extinction risk assessment of policy plant species? J. Nat. Conserv. 2018, 44, 43-49. [CrossRef]

7. Cafarchia, C.; De, L.N.; Milillo, M.A.; Losacco, V.; Puccini, V. Fungistatic activity of a sesquiterpene lactone (tomentosin) isolated from fresh Inula viscosa (Asteraceae) flowers from the Puglia region. Parassitologia 2001, 43, 117-121. [PubMed]

8. $\quad$ Park, H.-H.; Kim, S.-G.; Kim, M.J.; Lee, J.; Choi, B.-K.; Jin, M.-H.; Lee, E. Suppressive Effect of Tomentosin on the Production of Inflammatory Mediators in RAW264.7 Cells. Biol. Pharm. Bull. 2014, 37, 1177-1183. [CrossRef] [PubMed]

9. Hu, M.L.; Li, Y.Q.; Bai, M.; Wang, Y.L.; Wu, H. Variations in volatile oil yields and compositions of Magnolia zenii Cheng flower buds at different growth stages. Trees 2015, 29, 1649-1660. [CrossRef]

10. Azuma, H.; Thien, L.B.; Kawano, S. Molecular Phylogeny of Magnolia (Magnoliaceae) Inferred from cpDNA Sequences and Evolutionary Divergence of the Floral Scents. J. Plant. Res. 1999, 112, 291-306. [CrossRef]

11. Azuma, H.; García-Franco, J.G.; Rico-Gray, V.; Thien, L.B. Molecular phylogeny of the Magnoliaceae: The biogeography of tropical and temperate disjunctions. Am. J. Bot. 2001, 88, 2275-2285. [CrossRef] [PubMed]

12. Shen, Y.; Chen, K.; Cuihua Gu Shaoyu Zheng, L.M. Comparative and phylogenetic analyses of 26 Magnoliaceae species based on complete chloroplast genome sequences. Can. J. For. Res. 2018, 48, 1456-1469. [CrossRef]

13. Wu, W.; Chen, F.; Jing, D.; Liu, Z.; Ma, L. Isolation and Characterization of an AGAMOUS-Like Gene from Magnolia wufengensis (Magnoliaceae). Plant. Mol. Biol. Report. 2012, 30, 690-698. [CrossRef] 
14. Fang, H.; Yuan, Z. Studies on the Medicinal Plants of Chinese Magnoliaceae Analysis of the Constituents of the Volatile Oil from Flower Buds of Malznolia sargentiana. Chinese J. Pharm. Analysis 1988, 8, 266-269.

15. Lee, J.-Y.; Ko, S.-H.; Mun, S.-J.; You, J.-H.; Kim, S.-W. Investigation of Forest Therapeutic Function According to the Antioxidant Activity and Total Phenolics in Magnoliaceae Flower. J. Korean Inst. For. Recreat. 2013, 17, 81-86. [CrossRef]

16. Nooteboom, P.H.; Xia, N.; Yuhu, L. Magnoliaceae in Flora of China. Available online: http://www.efloras. org / florataxon.aspx?flora_id=2\&taxon_id=10530 (accessed on 9 November 2018).

17. Ma, F.; Liang, G. The Research Situation of Magnolia Linn. J. Guiyang College TCM 2015, 37, 92-96.

18. Sui-Chao, H.E. Phylogenetic Relationship Between Magnolia wufengensis and Several Related Species in Subgenus Yulania Based on AFLP Marker Analysis. Bull. Bot. Res. 2008, 28, 288-292.

19. Figlar, R.; Figlar, R.B. Proleptic branch initiation in Michelia and Magnolia subgenus Yulania provides basis for combinations in subfamily Magnolioideae. In The International Symposium on the Family Magnoliaceae; Science Press: Beijing, China, 1998; pp. 14-25.

20. Azuma, H.; Chalermglin, P.; Nooteboom, H.P. Molecular phylogeny of Magnoliaceae based on plastid DNA sequences with special emphasis on some species from continental Southeast Asia. Thai For. Bull. 2011, 39, 148-165.

21. Kim, S.; Park, C.W.; Kim, Y.D.; Suh, Y. Phylogenetic relationships in family Magnoliaceae inferred from $n d h F$ sequences. Am. J. Bot. 2001, 88, 717-728. [CrossRef]

22. Nie, Z.L.; Wen, J.; Azuma, H.; Qiu, Y.L.; Sun, H.; Meng, Y.; Sun, W.B.; Zimmer, E.A. Phylogenetic and biogeographic complexity of Magnoliaceae in the Northern Hemisphere inferred from three nuclear data sets. Mol. Phylogenet. Evol. 2008, 48, 1027-1040. [CrossRef]

23. Daniell, H.; Lin, C.-S.; Yu, M.; Chang, W.-J. Chloroplast genomes: Diversity, evolution, and applications in genetic engineering. Genome Biol. 2016, 17. [CrossRef] [PubMed]

24. Raman, G.; Park, V.; Kwak, M.; Lee, B.; Park, S.J. Characterization of the complete chloroplast genome of Arabis stellari and comparisons with related species. PLoS ONE 2017, 12, 1-18. [CrossRef]

25. Kress, W.J.; Wurdack, K.J.; Zimmer, E.A.; Weigt, L.A.; Janzen, D.H. Use of DNA barcodes to identify flowering plants. Proc. Natl. Acad. Sci. USA 2005, 102, 8369-8374. [CrossRef]

26. Ng, P.K.; Lin, S.M.; Lim, P.E.; Liu, L.C.; Chen, C.M.; Pai, T.W. Complete chloroplast genome of Gracilaria firma (Gracilariaceae, Rhodophyta), with discussion on the use of chloroplast phylogenomics in the subclass Rhodymeniophycidae. BMC Genomics 2017, 18, 1-16. [CrossRef] [PubMed]

27. Zeng, S.; Zhou, T.; Han, K.; Yang, Y.; Zhao, J.; Liu, Z.L. The complete chloroplast genome sequences of six rehmannia species. Genes 2017, 8. [CrossRef]

28. Zhao, J.; Xu, Y.; Xi, L.; Yang, J.; Chen, H.; Zhang, J. Characterization of the Chloroplast Genome Sequence of Acer miaotaiense: Comparative and Phylogenetic Analyses. Molecules 2018, 23. [CrossRef] [PubMed]

29. Li, X.-W.; Hu, Z.-G.; Lin, X.-H.; Li, Q.; Gao, H.-H.; Luo, G.-A.; Chen, S.-L. High-throughput pyrosequencing of the complete chloroplast genome of Magnolia officinalis and its application in species identification. Acta Pharm. Sin. 2012, 47, 124-130.

30. Li, X.; Gao, H.; Wang, Y.; Song, J.; Henry, R.; Wu, H.; Hu, Z.; Yao, H.; Luo, H.; Luo, K.; et al. Complete chloroplast genome sequence of Magnolia grandiflora and comparative analysis with related species. Sci. China Life Sci. 2013, 56, 189-198. [CrossRef] [PubMed]

31. Saina, J.K.; Gichira, A.W.; Li, Z.Z.; Hu, G.W.; Wang, Q.F.; Liao, K. The complete chloroplast genome sequence of Dodonaea viscosa: Comparative and phylogenetic analyses. Genetica 2018, 146, 101-113. [CrossRef] [PubMed]

32. Schmid, P.; Flegel, W.A. Codon usage in vertebrates is associated with a low risk of acquiring nonsense mutations. J. Transl. Med. 2011, 9, 87. [CrossRef]

33. De Abreu, N.L.; Alves, R.J.V.; Cardoso, S.R.S.; Bertrand, Y.J.K.; Sousa, F.; Hall, C.F.; Pfeil, B.E.; Antonelli, A. The use of chloroplast genome sequences to solve phylogenetic incongruences in Polystachya Hook (Orchidaceae Juss). PeerJ 2018, 6. [CrossRef] [PubMed]

34. Niu, D.K.; Yang, Y.F. Why eukaryotic cells use introns to enhance gene expression: Splicing reduces transcription-associated mutagenesis by inhibiting topoisomerase I cutting activity. Biol. Direct 2011, 6, 24. [CrossRef]

35. Le Hir, H.; Nott, A.; Moore, M.J. How introns influence and enhance eukaryotic gene expression. Trends Biochem. Sci. 2003, 28, 215-220. [CrossRef] 
36. Kuang, D.-Y.; Wu, H.; Wang, Y.-L.; Gao, L.-M.; Zhang, S.-Z.; Lu, L.; Bonen, L. Complete chloroplast genome sequence of Magnolia kwangsiensis (Magnoliaceae): Implication for DNA barcoding and population genetics. Genome 2011, 54, 663-673. [CrossRef] [PubMed]

37. Liu, H.-Y.; Yu, Y.; Deng, Y.-Q.; Li, J.; Huang, Z.-X.; Zhou, S.-D. The Chloroplast Genome of Lilium henrici: Genome Structure and Comparative Analysis. Molecules 2018, 23. [CrossRef] [PubMed]

38. Jian, H.-Y.; Zhang, Y.-H.; Yan, H.-J.; Qiu, X.-Q.; Wang, Q.-G.; Li, S.-B.; Zhang, S.-D. The Complete Chloroplast Genome of a Key Ancestor of Modern Roses, Rosa chinensis var. spontanea, and a Comparison with Congeneric Species. Molecules 2018, 23. [CrossRef]

39. Zhou, J.; Cui, Y.; Chen, X.; Li, Y.; Xu, Z.; Duan, B.; Li, Y.; Song, J.; Yao, H. Complete Chloroplast Genomes of Papaver rhoeas and Papaver orientale: Molecular Structures, Comparative Analysis, and Phylogenetic Analysis. Molecules 2018, 23. [CrossRef] [PubMed]

40. Provan, J.; Powell, W.; Hollingsworth, P.M. Chloroplast microsatellites: New tools for studies in plant ecology and evolution. Trends Ecol. Evol. 2001, 16, 142-147. [CrossRef]

41. McCauley, D.E. The use of chloroplast DNA polymorphism in studies of gene flow in plants. Trends Ecol. Evol. 1995, 10, 198-202. [CrossRef]

42. Deguilloux, M.-F.; Pemonge, M.-H.; Petit, R.J. Use of chloroplast microsatellites to differentiate oak populations. Ann. For. Sci. 2004, 61, 825-830. [CrossRef]

43. Shen, X.; Wu, M.; Liao, B.; Liu, Z.; Bai, R.; Xiao, S.; Li, X.; Zhang, B.; Xu, J.; Chen, S. Complete Chloroplast Genome Sequence and Phylogenetic Analysis of the Medicinal Plant Artemisia annua. Molecules 2017, 22. [CrossRef]

44. Xie, D.F.; Yu, Y.; Deng, Y.Q.; Li, J.; Liu, H.Y.; Zhou, S.D.; He, X.J. Comparative Analysis of the Chloroplast Genomes of the Chinese Endemic Genus Urophysa and Their Contribution to Chloroplast Phylogeny and Adaptive Evolution. Int. J. Mol. Sci. 2018, 19, 1847. [CrossRef] [PubMed]

45. Borsch, T.; Quandt, D. Mutational dynamics and phylogenetic utility of noncoding chloroplast DNA. Plant. Syst. Evol. 2009, 282, 169-199. [CrossRef]

46. F Costa, J.; Lin, S.M.; MacAya, E.C.; Fernández-Garciá, C.; Verbruggen, H. Chloroplast genomes as a tool to resolve red algal phylogenies: A case study in the Nemaliales. BMC Evol. Biol. 2016, 16, 1-13. [CrossRef]

47. Darling, A.C.E. Mauve: Multiple Alignment of Conserved Genomic Sequence With Rearrangements. Genome Res. 2004, 14, 1394-1403. [CrossRef] [PubMed]

48. Brudno, M.; Do, C.B.; Cooper, G.M.; Kim, M.F.; Davydov, E.; Green, E.D.; Sidow, A.; Batzoglou, S. LAGAN and Multi-LAGAN: Efficient tools for large-scale multiple alignment of genomic DNA. Genome Res. 2003, 13, 721-731. [CrossRef] [PubMed]

49. Zhu, A.; Guo, W.; Gupta, S.; Fan, W.; Mower, J.P. Evolutionary dynamics of the plastid inverted repeat: The effects of expansion, contraction, and loss on substitution rates. New Phytol. 2016, 209, 1747-1756. [CrossRef]

50. Satjarak, A.; Graham, L.E. Comparative DNA sequence analyses of Pyramimonas parkeae (Prasinophyceae) chloroplast genomes. J. Phycol. 2017, 53, 415-424. [CrossRef]

51. Saina, J.K.; Li, Z.Z.; Gichira, A.W.; Liao, Y.Y. The Complete Chloroplast Genome Sequence of Tree of Heaven (Ailanthus altissima (Mill.) (Sapindales: Simaroubaceae), an Important Pantropical Tree. Int. J. Mol. Sci. 2018, 19. [CrossRef]

52. Neubig, K.; Whitten, W.; Carlsward, B.; Blanco, M.; Endara, L.; Williams, N.; Moore, M. Phylogenetic utility of ycf1 in orchids: A plastid gene more variable than matK. Plant. Syst. Evol. 2009, 277, 75-84. [CrossRef]

53. Drescher, A.; Stephanie, R.; Calsa, T.; Carrer, H.; Bock, R. The two largest chloroplast genome-encoded open reading frames of higher plants are essential genes. Plant. J. 2000, 22, 97-104. [CrossRef] [PubMed]

54. Huang, J.L.; Sun, G.L.; Zhang, D.M. Molecular evolution and phylogeny of the angiosperm ycf2 gene. J. Syst. Evol. 2010, 48, 240-248. [CrossRef]

55. Dugas, D.V.; Hernandez, D.; Koenen, E.J.M.; Schwarz, E.; Straub, S.; Hughes, C.E.; Jansen, R.K.; Nageswara-Rao, M.; Staats, M.; Trujillo, J.T.; et al. Mimosoid legume plastome evolution: IR expansion, tandem repeat expansions, and accelerated rate of evolution in clpP. Sci. Rep. 2015, 5, 1-13. [CrossRef] [PubMed]

56. Resour, G.; Wang, G.; Hou, N.; Zhang, S.; Luo, Y. Characterization of the complete chloroplast genomes of seven Manglietia and one Michelia species (Magnoliales: Magnoliaceae). Conserv. Genet. Resour. 2017, 1. [CrossRef] 
57. Maier, U.G.; Karin, K.; Sabine, B.; Funk, H.T.; Kirsten, K. Complete DNA sequences of the plastid genomes of two parasitic flowering plant species, Cuscuta reflexa and Cuscuta gronovii. BMC Plant. Biol. 2007, 7, 1-12. [CrossRef]

58. Wicke, S.; Müller, K.F.; de Pamphilis, C.W.; Quandt, D.; Wickett, N.J.; Zhang, Y.; Renner, S.S.; Schneeweiss, G.M. Mechanisms of functional and physical genome reduction in photosynthetic and nonphotosynthetic parasitic plants of the broomrape family. Plant. Cell. 2013, 25, 3711-3725. [CrossRef] [PubMed]

59. Saski, C.; Lee, S.B.; Daniell, H.; Wood, T.C.; Tomkins, J.; Kim, H.G.; Jansen, R.K. Complete Chloroplast Genome Sequence of Glycine max and Comparative Analyses with other Legume Genomes. Plant. Mol. Biol. 2005, 59, 309-322. [CrossRef] [PubMed]

60. Schwarz, E.N.; Ruhlman, T.A.; Sabir, J.S.M.; Hajrah, N.H.; Alharbi, N.S.; Al-Malki, A.L.; Bailey, C.D.; Jansen, R.K. Plastid genome sequences of legumes reveal parallel inversions and multiple losses of rps16 in papilionoids. J. Syst. Evol. 2015, 53, 458-468. [CrossRef]

61. Chumley, T.W.; Palmer, J.D.; Mower, J.P.; Fourcade, H.M.; Calie, P.J.; Boore, J.L.; Jansen, R.K. The complete chloroplast genome sequence of Pelargonium $\mathrm{x}$ hortorum: Organization and evolution of the largest and most highly rearranged chloroplast genome of land plants. Mol. Biol. Evol. 2006, 23, 2175-2190. [CrossRef]

62. Shaw, J.; Lickey, E.B.; Schilling, E.E.; Small, R.L. Comparison of whole chloroplast genome sequences to choose noncoding regions for phylogenetic studies in angiosperms: The Tortoise and the hare III. Am. J. Bot. 2007, 94, 275-288. [CrossRef]

63. Niu, Z.; Xue, Q.; Zhu, S.; Sun, J.; Liu, W.; Ding, X. The Complete Plastome Sequences of Four Orchid Species: Insights into the Evolution of the Orchidaceae and the Utility of Plastomic Mutational Hotspots. Front. Plant. Sci. 2017, 8. [CrossRef] [PubMed]

64. Figlar, R.B. Magnolia Classification. Available online: https://www.magnoliasociety.org/Classification (accessed on 9 November 2018).

65. Qiu, Y.-L.; Chase, M.W.; Parks, C.R. A Chloroplast Eastern Section Study Rytidospermum of Magnolia. Am. J. Bot. 1995, 82, 1582-1588. [CrossRef]

66. Doyle, J.J.; Doyle, J.L. A Rapid DNA Isolation Procedure for Small Quantities of Fresh Leaf Tissue. Phytochem. Bull. 1987, 19, 11-15.

67. Dierckxsens, N.; Mardulyn, P.; Smits, G. NOVOPlasty: De novo assembly of organelle genomes from whole genome data. Nucleic Acids Res. 2016, 45. [CrossRef]

68. Liu, C.; Shi, L.; Zhu, Y.; Chen, H.; Zhang, J.; Lin, X.; Guan, X. CpGAVAS, an integrated web server for the annotation, visualization, analysis, and GenBank submission of completely sequenced chloroplast genome sequences. BMC Genomics 2012, 13. [CrossRef] [PubMed]

69. Lohse, M.; Drechsel, O.; Bock, R. OrganellarGenomeDRAW (OGDRAW): A tool for the easy generation of high-quality custom graphical maps of plastid and mitochondrial genomes. Curr. Genet. 2007, 52, 267-274. [CrossRef] [PubMed]

70. Peden, J.F. Analysis of codon usage. Biosystems. 1999, 5, 45-50.

71. Doose, D.; Grand, C.; Lesire, C. MAUVE runtime: A component-based middleware to reconfigure software architectures in real-time. Robotic Computing (IRC), IEEE International Conference, Taichung, Taiwan, 10-12 April 2017, IEEE: Taichung, Taiwan, 2017; pp. 208-211.

72. Mayor, C.; Brudno, M.; Schwartz, J.R.; Poliakov, A.; Rubin, E.M.; Frazer, K.A.; Pachter, L.S.; Dubchak, I. Vista: Visualizing global DNA sequence alignments of arbitrary length. Bioinformatics 2000, 16, 1046-1047. [CrossRef]

73. Frazer, K.A.; Pachter, L.; Poliakov, A.; Rubin, E.M.; Dubchak, I. VISTA: Computational tools for comparative genomics. Nucleic Acids Res. 2004, 32, 273-279. [CrossRef]

74. Brudno, M.; Malde, S.; Poliakov, A.; Do, C.B.; Couronne, O.; Dubchak, I.; Batzoglou, S. Glocal alignment: Finding rearrangements during alignment. Bioinformatics 2003, 19. [CrossRef]

75. Amiryousefi, A.; Hyvönen, J.; Poczai, P. IRscope: An online program to visualize the junction sites of chloroplast genomes. Bioinformatics 2018, 34, 3030-3031. [CrossRef] [PubMed]

76. Librado, P.; Rozas, J. DnaSP v5: A software for comprehensive analysis of DNA polymorphism data. Bioinformatics 2009, 25, 1451-1452. [CrossRef] [PubMed]

77. Kurtz, S.; Schleiermacher, C. REPuter: Fast computation of maximal repeats in complete genomes. Bioinformatics 1999, 15, 426-427. [CrossRef] [PubMed] 
78. Kurtz, S. REPuter: The manifold applications of repeat analysis on a genomic scale. Nucleic Acids Res. 2001, 29, 4633-4642. [CrossRef] [PubMed]

79. Thiel, T.; Michalek, W.; Varshney, R.K.; Graner, A. Exploiting EST databases for the development and characterization of gene-derived SSR-markers in barley (Hordeum vulgare L.). Theor. Appl. Genet. 2003, 106, 411-422. [CrossRef]

80. Katoh, K.; Standley, D.M. MAFFT multiple sequence alignment software version 7: Improvements in performance and usability. Mol. Biol. Evol. 2013, 30, 772-780. [CrossRef]

81. Hall, T.A. BioEdit: A user-friendly biological sequence alignment editor and analysis program for Windows 95/98/NT. Nucleic Acids Symp. Ser. 1999, 41, 95-98.

82. Darriba, D.; Taboada, G.L.; Doallo, R.; Posada, D. jModelTest 2: More models, new heuristics and parallel computing. Nat. Methods 2012, 9, 772. [CrossRef]

83. Akaike, H. A new look at the statistical model identification. IEEE Trans. Automat. Contr. 1974, 19, 716-723. [CrossRef]

84. Pol, D. Empirical problems of the hierarchical likelihood tatio test for model selection. Syst. Biol. 2004, 53, 949-962. [CrossRef]

85. Posada, D.; Buckley, T.R. Model selection and model averaging in phylogenetics: Advantages of akaike information criterion and bayesian approaches over likelihood ratio tests. Syst. Biol. 2004, 53, 793-808. [CrossRef] [PubMed]

86. Miller, M.A.; Pfeiffer, W.; Schwartz, T. Creating the CIPRES Science Gateway for inference of large phylogenetic trees. In 2010 Gateway Computing Environments Workshop (GCE), New Orleans, LA, USA, 14 November 2010; IEEE: New Orleans, LA, USA, 2010.

87. Stamatakis, A.; Hoover, P.; Rougemont, J. A rapid bootstrap algorithm for the RAxML web servers. Syst. Biol. 2008, 57, 758-771. [CrossRef] [PubMed]

88. Ronquist, F.; Huelsenbeck, J.P. MrBayes 3: Bayesian phylogenetic inference under mixed models. Bioinformatics 2003, 19, 1572-1574. [CrossRef] [PubMed]

89. Booy, G.; Hendriks, R.J.J.; Smulders, M.J.M.; Van Groenendael, J.M.; Vosman, B. Genetic diversity and the survival of populations. Plant. Biol. 2000, 2, 379-395. [CrossRef]

90. Breed, M.F.; Stead, M.G.; Ottewell, K.M.; Gardner, M.G.; Lowe, A.J. Which provenance and where? Seed sourcing strategies for revegetation in a changing environment. Conserv. Genet. 2013, 14, 1-10. [CrossRef]

91. Byrne, M.; Stone, L.; Millar, M.A. Assessing genetic risk in revegetation. J. Appl. Ecol. 2011, 48, $1365-1373$. [CrossRef]

Sample Availability: The annotated plastid genome sequence of M. zenii was deposited in GenBank (Accession number MH607378). Samples of the compounds are available from the authors. 